\title{
Role of intraoperative ultrasound examination in patients undergoing a Fontan-type procedure
}

Oliver Stümper, George R Sutherland, Narayanswami Sreeram, Marc E R M van Daele, John Hess, Egbert Bos, Jan M Quaegebeur

\begin{abstract}
To determine its potential impact on perioperative surgical management intraoperative ultrasound examination (cross sectional imaging, colour flow mapping, pulsed and continuous wave Doppler) was used in 16 consecutive patients undergoing a Fontan-type procedure. Epicardial cross sectional imaging before bypass defined the precise intracardiac morphology in 15 of 16 patients. The preoperative morphological diagnosis was refined in four patients $(25 \%)$, and this influenced surgical management in two (12\%). Epicardial studies after bypass identified seven residual haemodynamic lesions in five patients (three residual intercardiac shunts, one ventricular outflow obstruction, one pulmonary artery obstruction, two mitral valve regurgitation), and led to immediate revision during a second period of bypass in three $(18 \%)$. In one patient who required early reoperation residual shunting was not detected after bypass by either colour flow mapping or a contrast study. Final intraoperative studies showed a good surgical result in 14 patients $(87 \%)$. Flow characteristics and flow velocities within the Fontan circulation could be assessed immediately after the patient came off cardiopulmonary bypass by means of combined pulsed wave Doppler and colour flow mapping in 14 of the 16 patients. Cross sectional studies of the left heart after bypass showed no change in ventricular function and allowed monitoring of volume replacement and ventricular filling.

Intraoperative ultrasound was a valuable monitoring technique in patients undergoing a Fontan-type procedure. It refined preoperative diagnosis, monitored ventricular function, and identified or excluded residual haemodynamic lesions in most patients.
\end{abstract}

The Fontan procedure or one of its modifications is widely used to correct a wide range of complex congenital heart lesions. ${ }^{1-3}$ Both the operative mortality and reported results in the intermediate term have improved remarkably over the past decade. ${ }^{3-5}$ In several large series of patients, ${ }^{4-6}$ however, residual haemodynamic lesions were common (14-29\%) and some caused early deaths in hospital, required early reoperation, or impaired functional capacity. ${ }^{7-9}$ We need an intraoperative monitoring technique for the rapid and accurate identification of important residual lesions immediately after a Fontan circulation has been established. This would allow the repair of important residual lesions during the same operation in a second period of bypass, and might further improve the early results of operation.

During operations for congenital heart disease high resolution epicardial cross sectional imaging can be used to define abnormal cardiac morphology before bypass and a combination of colour flow mapping and spectral Doppler investigations can be used to assess the haemodynamic results achieved by the surgical repair. ${ }^{10-12}$ Epicardial cardiac ultrasound might also be useful for the immediate evaluation of the results achieved by a Fontan-type procedure. To test this premise we used the full range of ultrasound investigations in a series of patients undergoing a Fontan-type procedure.

\section{Patients and methods}

Sixteen patients who underwent a Fontantype procedure at the Department for Cardiothoracic Surgery, Erasmus University, Rotterdam were entered into a prospective intraoperative ultrasound study to determine the impact of such an examination on perioperative surgical management.

\section{PATIENTS}

The age at operation ranged from 5 months to 33 years (median age 3 years 6 months) and the body weight ranged from $4400 \mathrm{~g}$ to $73 \mathrm{~kg}$. The preoperative diagnosis (table 1) was absent right connection (tricuspid atresia) in 10 patients, double inlet left ventricle in four patients, "criss-cross" heart in one patient (case 3), and a congenitally corrected transposition (discordant-discordant connections) with a straddling tricuspid valve in one patient (case 13). All patients had situs solitus of the atria; four patients had dextrocardia. Two patients (cases 10 and 16) were known to have mild mitral valve regurgitation before operation.

Eleven patients had had palliative procedures (nine left Blalock shunts, one right Blalock shunt, two central shunts, one Waterston shunt, one pulmonary artery banding, one enlargement of a ventricular septal defect (table 1). 
Table 1 Patient data, diagnosis, previous palliation, and surgical procedure

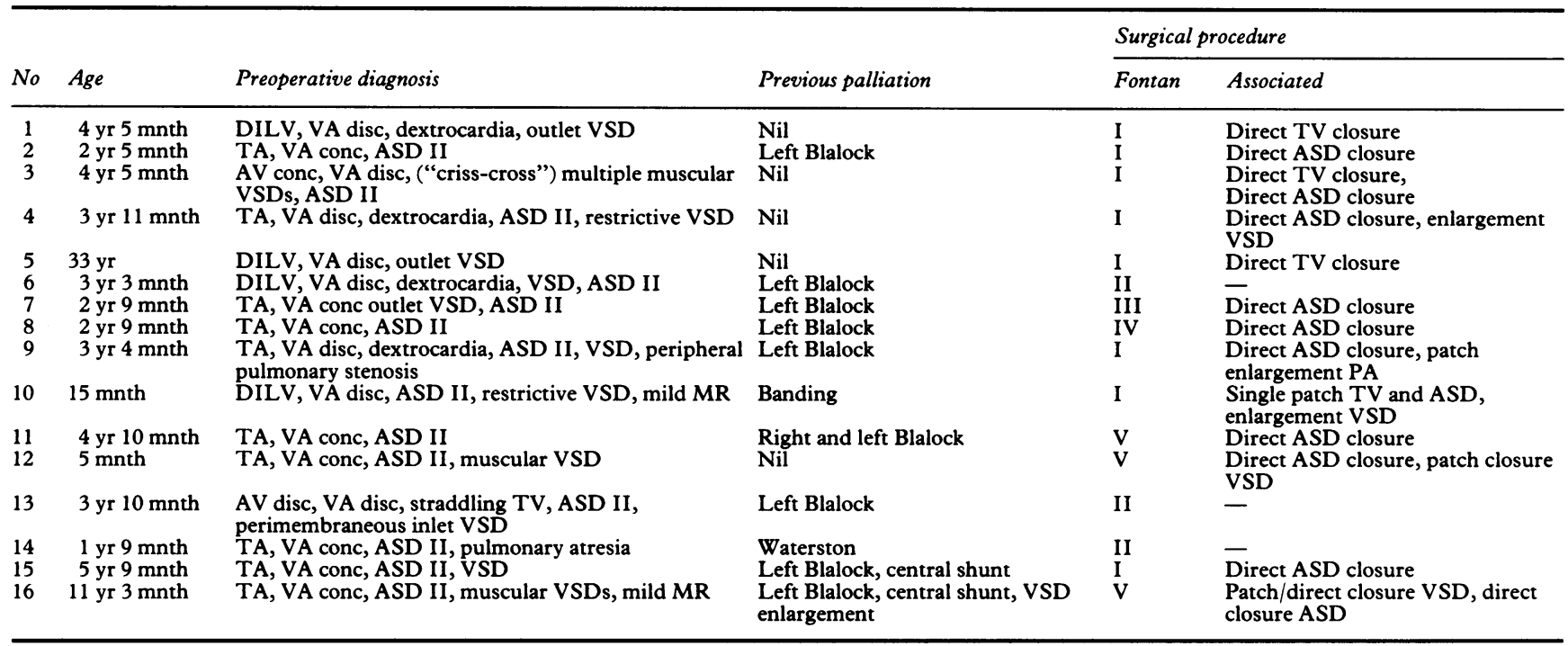

ASD II, secundum atrial septal defect; AV, atrioventricular; conc, concordance; disc, discordance; DILV, double inlet left ventricle; MR, mitral regurgitation; PA, pulmonary artery; TA, tricuspid atresia; TV, tricuspid valve; VA, ventriculoarterial; VSD, ventricular septal defect; Fontan procedures: I = direct atriopulmonary anastomosis; II = total cavopulmonary connection; III = modified Kreutzer procedure; IV = valved (homograft) atriopulmonary connection; V = valved (homograft) atrioventricular connection.

OPERATION

The surgical techniques used to achieve systemic venous to pulmonary artery connections (Fontan-type procedures) were (a) direct atriopulmonary anastomosis (retroaortic) in eight patients, (b) total cavopulmonary connection ${ }^{13}$ by use of a prosthetic patch (three patients), (c) a Kreutzer procedure (right atrial appendage to main pulmonary artery connection incorporating the pulmonary valve) in one patient, (d) valved atriopulmonary connection (homograft conduit) in one patient with tricuspid atresia and a hypoplastic main pulmonary artery, and $(e)$ valved atrioventricular connection (homograft conduit) in three patients with tricuspid atresia and ventriculoarterial concordance (table 1 ).

Secundum type atrial septal defects in 10 patients with tricuspid atresia were closed by means of a double layer of running sutures in nine patients. The defect was left open in one patient who underwent an operation for total cavopulmonary connection (case 2). Eight patients with tricuspid atresia had concordant ventriculoarterial connections. Three of these underwent an operation to construct a valved atrioventricular connection; this required closure of ventricular septal defect(s) in two (cases 12 and 16). Enlargement of a restrictive ventricular septal defect was required in one (case 4) of two patients with ventriculoarterial discordance.

All four patients with double inlet left ventricle had ventriculoarterial discordance. Three of these underwent a direct atriopulmonary anastomosis. The tricuspid valve was closed with a double layer of interrupted mattress sutures in two patients with an intact atrial septum (cases 1 and 5) and a pericardial patch was used to close both the tricuspid valve and the secundum atrial septal defect in one (case 10). This latter patient also required enlargement of a restrictive ventricular septal defect because of ventriculoarterial discordance. One patient with double inlet left ventricle (case 6) underwent an operation to form a total cavopulmonary connection; the atrial septal defect was left open.

One patient with a preoperative diagnosis of "criss-cross" heart (case 3) underwent direct atriopulmonary anastomosis with direct closure of both the tricuspid valve and the atrial septal defect. The patient with congenitally corrected transposition and a straddling tricuspid valve (case 13) underwent a total cavopulmonary anastomosis, without closure of the atrial septal defect.

\section{ECHOCARDIOGRAPHY}

Intraoperative epicardial studies were performed with a Toshiba SSH 65 or a Toshiba SSH 160 A ultrasound system in all 16 patients before and after cardiopulmonary bypass. The scanning equipment consisted of multiple standard precordial transducers: a $5 \mathrm{MHz}$ transducer for high resolution cross sectional imaging plus a $3.75 \mathrm{MHz}$ transducer for colour flow mapping and pulsed wave Doppler investigations, and in two patients a $2.5 \mathrm{MHz}$ continuous wave Doppler duplex probe. The probes and wires were packed in sterile tube-shaped plastic bags after about $5 \mathrm{ml}$ of sterile ultrasound coupling gel had been applied to the tip of the transducer. After packing, the probes were passed into the operative field where they remained during the entire operation.

Studies were performed either by a paediatric cardiologist or the cardiac surgeon and were entirely recorded on video tape to allow subsequent off line interpretaton. The studies before bypass lasted about 5 minutes and those after bypass about 10 minutes. The studies were interpreted on line and the find- 
ings were discussed. Immediately after completion further off line analysis was carried out in the echocardiography laboratory.

Pre-bypass studies were performed after median sternotomy and pericardiotomy. Warm saline was poured into the pericardial cradle to improve contact between the epicardium and the transducer and to reduce mechanical irritation of the heart. Cross sectional imaging was performed first. Results were correlated with the preoperative findings and with the findings at surgical inspection. Then haemodynamic function was assessed by colour flow mapping of the entire heart. These morphological and haemodynamic ultrasound findings served as a reference for the subsequent studies after bypass.

Post-bypass studies were performed after the removal of all cannulas for cardiopulmonary bypass, because these may cause unpredictable flow patterns, and as soon as haemodynamic function was relatively stable. Cross sectional imaging was used to assess the surgical repair and together with $M$ mode tracings to monitor ventricular function. Colour flow mapping of the entire heart and the Fontan circulation was used to detect any flow obstructions across the anastomoses, residual intracardiac shunting, incompetence of atrioventricular valves, or ventricular outflow obstructions. Pulsed wave Doppler investigations were performed to trace and measure flow velocities across the Fontan circulation. Continuous wave Doppler was used to assess blood flow through the ventricular septal defect in two patients with ventriculoarterial discordance. Contrast echocardiographic studies, for the exclusion of residual interatrial shunting, were performed to confirm the findings at colour flow mapping. Routinely $2-5 \mathrm{ml}$ of hand-agitated patient's blood was used as the contrast medium. This was injected via a right atrial line while a modified four chamber view was scanned from the mid-portion of the right ventricle.

\section{Results}

STUDIES BEFORE BYPASS

A combination of high resolution cross sectional epicardial imaging and colour flow mapping confirmed the preoperative diagnosis in 11 of the 16 patients. The diagnosis was refined in four patients $(25 \%)$, and this influenced surgical management in two (12\%) (table 2). In one of these patients (case 3 ) both atrioventricular valves and their tensor apparatus were shown to be entirely connected to the left ventricle, changing the preoperative diagnosis of "criss-cross" heart to double inlet left ven- tricle. This new finding was, however, of no surgical relevance. In one patient (case 7) with a secundum type atrial septal defect an additional low posterior fenestrated defect was detected. In two patients (cases 11 and 16) with ventriculoarterial concordance epicardial cross sectional imaging clearly showed a right ventricular chamber of moderate size and good function plus the absence of any valvar or subvalvar obstruction. This information, in both patients scheduled for construction of a direct atriopulmonary connection, allowed the outlet chamber to be incorporated into the Fontan circulation.

The information obtained by cross sectional imaging before bypass was verified at surgical inspection whenever feasible, and was found to be exact and complete in 15 out of 16 patients. In one patient with multiple muscular ventricular septal defects (case 16) the epicardial study before bypass showed only one large muscular defect and did not identify the additional defects. These were only identified at surgical inspection after the muscular obstruction between the trabecular and outlet portions of the right ventricle had been relieved. Colour flow mapping before bypass allowed assessment of haemodynamic function immediately before the repair and, even more importantly, served as the reference for interpretation of the subsequent study after bypass.

\section{STUDIES AFTER BYPASS}

Table 3 lists the residual lesions identified and their surgical consequences.

\section{Atrial septal defects}

After repair the perfect closure of atrial septal defects was assessed by colour flow mapping along a series of foreshortened four chamber views from the right ventricular and right atrial epicardium. A residual defect at the posteroinferior border of the surgical closure site (direct suture) was detected in one patient (case 7 ; table 2) in whom an additional low posterior fenestrated defect was found before bypass. Colour flow mapping showed its precise site and the restrictive flow pattern of the continuous right-to-left shunt. Residual shunting was reconfirmed by contrast injection into the right atrial line. Immediate revision during a second period of bypass effected closure of the defect; this was confirmed by colour flow mapping and a contrast study (fig 1).

\section{Ventriculoatrial communications}

Colour flow mapping studies after bypass showed a residual ventriculoatrial communication in one patient (case 5). A high velocity jet

Table 2 Refinement of the preoperative diagnosis by studies before bypass and influence on surgical management

\begin{tabular}{|c|c|c|c|}
\hline No & Preoperative & Study diagnosis before bypass & Influence on surgical management \\
\hline $\begin{array}{l}3 \\
7\end{array}$ & $\begin{array}{l}\text { Criss cross heart } \\
\text { Secundum ASD }\end{array}$ & $\begin{array}{l}\text { Double inlet left ventricle } \\
\text { Additional low posterior fenestrated } \\
\text { ASD }\end{array}$ & $\begin{array}{l}\text { No influence } \\
\text { No influence }\end{array}$ \\
\hline 11 & $\begin{array}{l}\text { Size and morphology of RV chamber } \\
\text { unknown, intact IVS }\end{array}$ & $\begin{array}{l}\text { RV of good size, no infundibular } \\
\text { stenosis, normal PV }\end{array}$ & Valved atrioventricular connection \\
\hline 16 & $\begin{array}{l}\text { Size and morphology of RV chamber } \\
\text { unknown }\end{array}$ & RV chamber of good size & Valved atrioventricular connection \\
\hline
\end{tabular}

ASD, atrial septal defect; IVS, interventricular septum; PV, pulmonary valve; $R V$, right ventricle. 


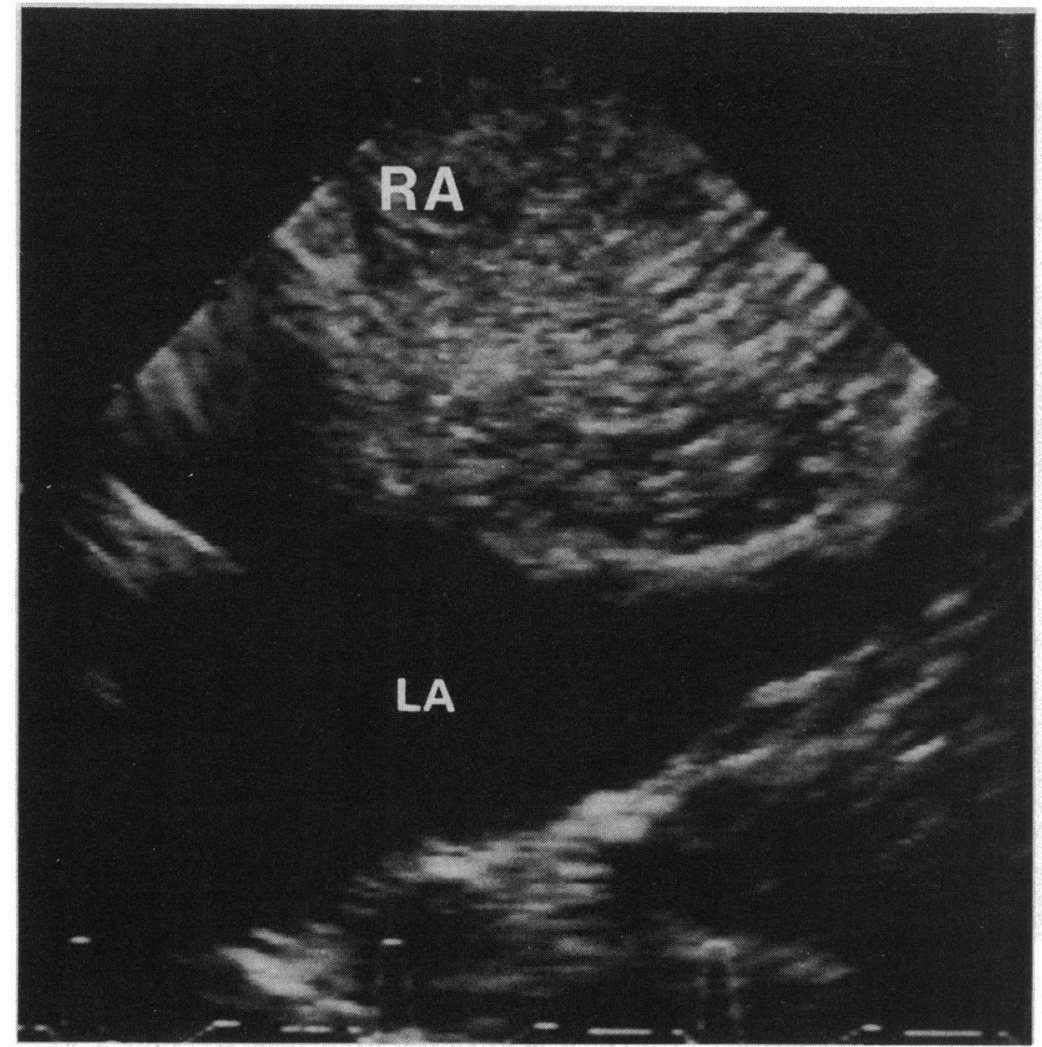

Figure 1 Contrast echocardiographic study after immediate revision of a small residual interatrial shunt (patient 7). After right atrial injection of hand agitated contrast medium, the right atrial cavity was uniformly opacified, whereas there was no sign of contrast in the left atrium. This showed the perfect closure of the residual defect. $L A$, left atrium; $R A$, right atrium. originating from the site of primary closure of the right atrioventricular valve was shown to reach far into the cavity of the right atrium. Immediate revision during a second period of bypass (pericardial patch closure) achieved perfect closure of the tricuspid valve. In the remaining three patients who underwent closure of a right sided atrioventricular valve colour flow mapping excluded any residual communication; this was reconfirmed by contrast studies (left atrial injection) in two.

\section{Leakage from intra-atrial tunnels}

In three patients a total cavopulmonary connection was created. Cross-sectional imaging after bypass showed the course of the tunnel, both venae cavae, and the anastomoses with the pulmonary artery system in two of the three patients. The colour flow mapping studies that were used to exclude residual shunting were judged to be satisfactory in only one patient.
Studies after bypass were limited by the altered geometry of the right atrium and the flow masking properties of the prosthetic material used in the repair. Contrast studies with injection into the right atrial line gave one false negative and one false positive result. Postoperative studies in the intensive care unit (contrast and oxygen saturations) showed residual shunting in one patient (false negative result after bypass), who subsequently underwent reoperation. At reoperation residual communications through the small trabeculations were found between the base of the right atrial appendage and the linea terminalis. The suture line of the patch was found to be intact.

\section{Ventricular septal defects}

In seven of the eight patients with ventriculoarterial discordance, colour flow mapping and pulsed and continuous wave Doppler studies after bypass showed an unobstructed ventricular outflow. In one patient the ventricular septal defect was found to be severely restrictive after bypass, whereas it had been shown to be unrestrictive both before operation and during studies before bypass. The maximal flow velocity measured by continuous wave Doppler was about $3.8 \mathrm{~m} / \mathrm{s}$, representing a pressure gradient of about $58 \mathrm{~mm} \mathrm{Hg}$. Immediate revision during a second period of bypass reduced the pressure gradient to $12 \mathrm{~mm} \mathrm{Hg}$.

Two of three patients with tricuspid atresia and ventriculoarterial concordance who had valved atrioventricular connections created had patch closure of a ventricular septal defect. In one of these patients (case 16) additional muscular defects were found at surgical inspection and subsequently closed. The cross sectional imaging study after bypass showed a small residual muscular defect. Off line analysis of the study after bypass showed systolic leftto-right shunting and diastolic right-to-left shunting (fig 2) caused by raised right atrial and ventricular pressures.

\section{Fontan circulation}

Cross sectional imaging did not show any anatomical obstruction to the pulmonary artery flow in 14 of 15 patients with satisfactory studies. In one patient (case 14) the study was incomplete after total cavopulmonary connection. Evidence of homograft valve closure was found in all three patients with an atrioventricular connection (cases 11, 12, and 16) and pulmonary valve closure in the patient with a Kreutzer procedure (case 7). The valve leaflets

Table 3 Identification of residual lesions by colour flow mapping and Doppler studies after bypass and the surgical consequences

\begin{tabular}{|c|c|c|c|c|}
\hline No & Diagnosis & Surgical procedure & Residual lesion & Immediate revision \\
\hline 5 & DILV, AV disc, unrestrictive VSD & \multirow{5}{*}{$\begin{array}{l}\text { Atriopulmonary conn, direct closure } \\
\text { of TV } \\
\text { Modified Kreutzer, direct suture } \\
\text { ASDs } \\
\text { Atriopulmonary conn, single patch } \\
\text { TV, ASD, enlargement VSD } \\
\text { Atriopulmonary conn, direct suture } \\
\text { ASD } \\
\text { Atrioventricular conn, direct closure } \\
\text { ASD, patch closure large VSD, } \\
\text { direct suture apical VSD }\end{array}$} & \multirow{3}{*}{$\begin{array}{l}\text { Ventriculoatrial shunt, restrictive } \\
\text { VSD } \\
\text { Residual interatrial shunt at } \\
\text { posteroinferior border } \\
\text { MR (increased) }\end{array}$} & $\begin{array}{l}\text { Patch closure TV, VSD } \\
\text { enlargement }\end{array}$ \\
\hline 7 & $\begin{array}{l}\text { TA, VA conc, VSD, ASD II, } \\
\text { additional fenestrated ASD }\end{array}$ & & & Re-closure \\
\hline 10 & $\begin{array}{l}\text { DILV, VA disc, ASD II, restrictive } \\
\text { VSD, mild MR }\end{array}$ & & & No \\
\hline 15 & TA, VA conc, ASD II, VSD & & \multirow{2}{*}{$\begin{array}{l}\text { Compression of left pulmonary } \\
\text { artery } \\
\text { Residual muscular VSD, MR } \\
\text { (unchanged) }\end{array}$} & Patch enlargement of bifurcation \\
\hline 16 & $\begin{array}{l}\text { TA, VA conc, ASD II, muscular } \\
\text { VSDs, mild MR }\end{array}$ & & & No \\
\hline
\end{tabular}

DILV, double inlet ventricle of left ventricular morphology; TA, tricuspid atresia; ASD II, secundum type atrial septal defect; VA, ventriculoarterial; conc, concordance; disc, discordance; VSD, ventricular septal defect; TV, tricuspid valve; conn, connection; MR, mitral regurgitation. 


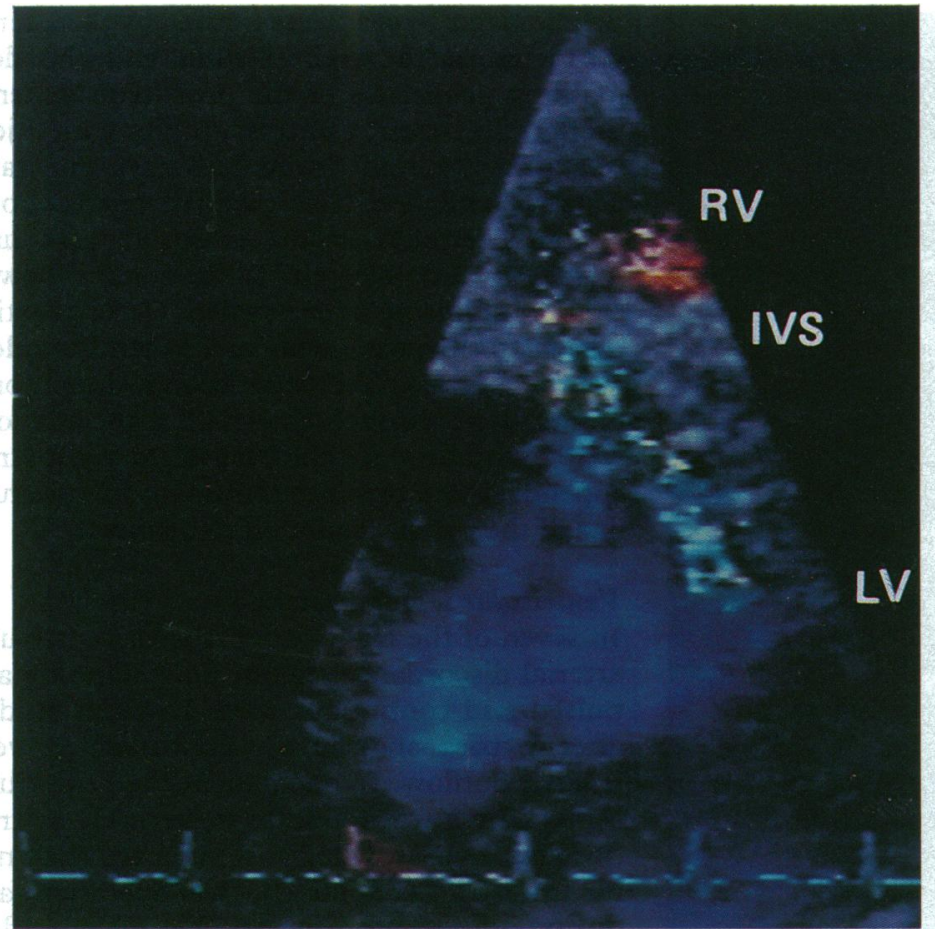

Figure 2 Residual interventricular shunting detected by colour flow mapping in patient 16 with tricuspid atresia, ventriculoarterial concordance, and multiple muscular ventricular septal defects. The mid-diastolic frame shows right-to-left shunting on the ventricular level (encoded in blue) with some flow turbulence. $R V$, right ventricle; IVS, interventricular septum; $L V$, left ventricle. remained partly open in the one patient (case 8) in whom a valved atriopulmonary connection had been constructed.

Colour flow mapping showed laminar (that is, unobstructed) flow within the Fontan circulation in 13 of 14 patients with satisfactory studies. Studies were unsatisfactory in two patients with total cavopulmonary connections (cases 13 and 14). In one patient (case 15), in whom cross sectional imaging showed a narrow left pulmonary artery, colour flow mapping showed considerable obstruction at the origin of the left pulmonary artery (fig 3A). Pulsed wave Doppler echocardiography showed continuous turbulent flow distal to the obstruction with a velocity of $1.5 \mathrm{~m} / \mathrm{s}$, representing a pressure gradient of about $4-5 \mathrm{~mm} \mathrm{Hg}$. The stenosis was caused by compression from the ascending aorta. This was proved when anterior displacement of the aorta resulted in laminar unobstructed flow (fig 3B). Subsequent patch enlargement of the bifurcation during a second period of bypass established unobstructed laminar flow into the left pulmonary artery (fig 3C), with a maximal flow velocity of less than $1.0 \mathrm{~m} / \mathrm{s}$ (fig 3D).

We assessed blood flow velocities and flow patterns within the Fontan circulation after bypass by pulsed wave Doppler investigations. Sample volumes were placed distal to the anastomoses or distal to any valve incorporated in the circulation. In patients with direct atriopulmonary anastomoses blood flow was found to be biphasic and bidirectional. Peak flow velocities ranged from 0.4 to $0.65 \mathrm{~m} / \mathrm{s}$ and occurred during late diastole. The second peak occurred during late ventricular systole and ranged from 0.2 to $0.3 \mathrm{~m} / \mathrm{s}$. Retrograde flow was detected during early ventricular systole and early diastole. After total cavopulmonary anastomosis a non-pulsatile, low velocity flow pattern with considerable respiratory changes was noted. Two patients with valved atrioventricular connections (cases 11 and 12) showed biphasic forward flow, with velocity peaks in the main pulmonary artery of 0.25 and $0.3 \mathrm{~m} / \mathrm{s}$ during late diastole and of 0.6 and $0.9 \mathrm{~m} / \mathrm{s}$ during ventricular systole, indicating the contribution of the right ventricle to pulmonary blood flow. In the third patient with a valved atrioventricular connection (case 16) no ventricular augmentation was noted.

Mitral valve regurgitation

Mild mitral valve regurgitation was shown by colour flow mapping in two patients immediately after bypass. One patient (case 10) showed atrioventricular dissociation, necessitating epicardial pacing. The regurgitant jet was considerably larger than that shown during the study before bypass. In the second patient (case 16) the severity of mitral regurgitation was judged to be unchanged.

\section{Ventricular function}

Left ventricular function was assessed before and after bypass by a series of short axis scans through the left ventricle. No regional wall motion abnormalities were noted in any patient and ventricular function was unchanged compared with the studies before bypass. In four patients short axis scans were used to monitor volume replacement and ventricular filling while the patient was weaned from cardiopulmonary bypass. In a further two patients the studies helped to determine the dosage of inotropic support.

\section{Complications}

Complications induced by direct contact epicardial imaging, apart from occasional episodes of self terminating short runs of ventricular extrasystoles (maximum five in succession), were not encountered. Medical treatment or electical cardioversion were never required. Sterility was preserved by packing the probes into long sterile plastic bags. No episode of endocarditis, pericarditis, or mediastinitis was reported during the study period.

\section{Discussion}

We studied the impact of intraoperative echocardiography in patients undergoing a Fontan-type procedure on perioperative surgical management.

Cross sectional imaging before bypass allowed detailed insights into the individual intracardiac morphology and contributed to surgical management in $12 \%$ of the patients. In one case the diagnosis before bypass was incomplete because additional muscular ventricular septal defects were not shown; turbulent flow in the entire small right ventricular cavity prevented the recognition of multiple individual jets by colour flow mapping. 
Figure 3 Study after bypass in patient 15 with severe pulmonary artery obstruction. (A) Colour flow mapping showing continuous turbulent flow just distal to the bifurcation caused by compression by the ascending aorta. ( $B$ )

Lifting up of the aorta allows laminar,

unobstructed flow in the left pulmonary artery,

establishing the cause of obstruction. (C) After patch enlargement of the bifurcation and the proximal left pulmonary artery flow was

unobstructed. (D) Pulsed wave Doppler sampling showed unobstructed flow. The maximal flow velocity was less than $1 \mathrm{~m} / \mathrm{s}$. Ao, ascending aorta; $l$, left; $P A$, pulmonary artery.
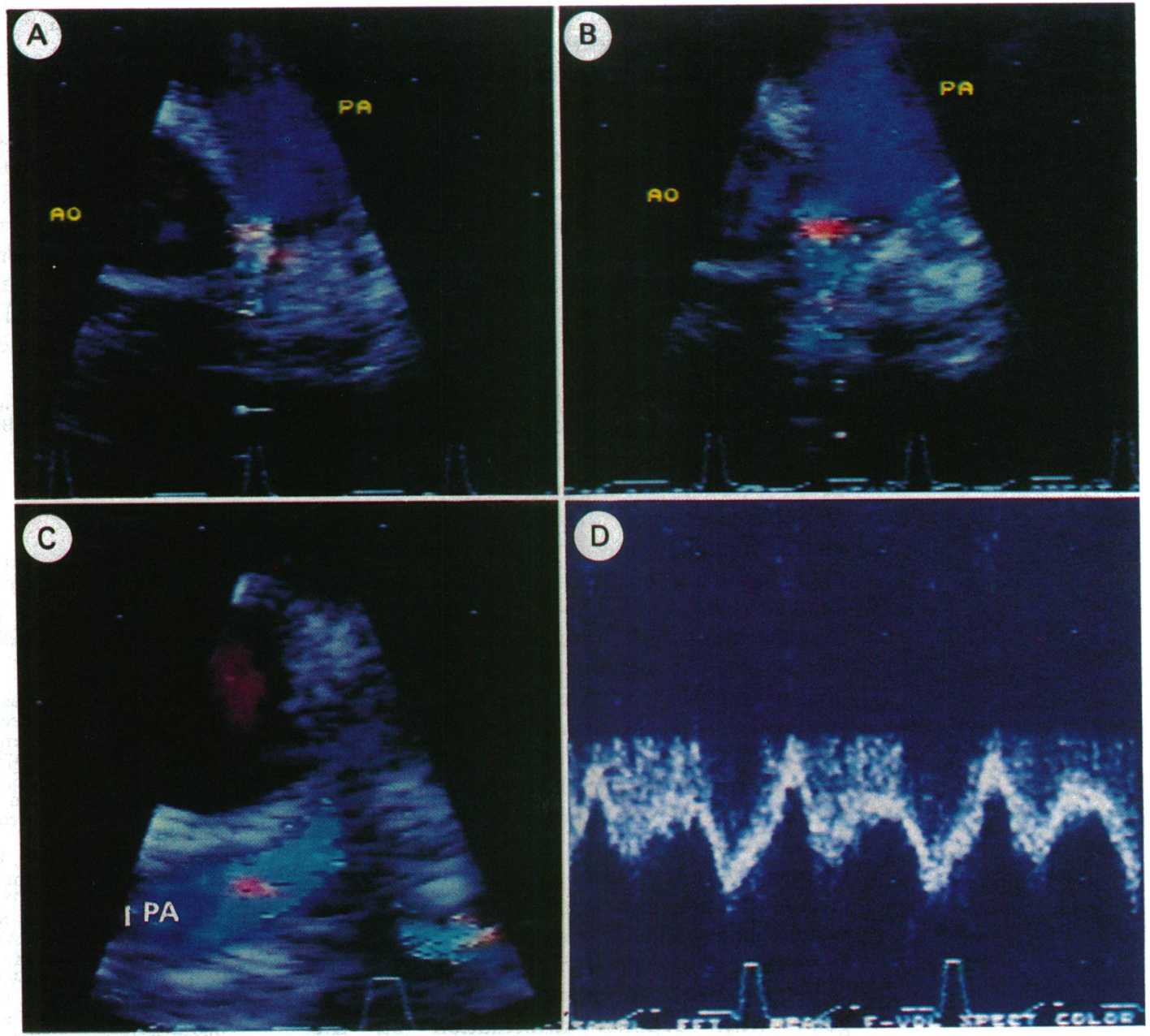

Ultrasound studies after bypass proved to be a valuable technique for the assessment of the surgical repair performed, for monitoring left ventricular filling and function, and for the exclusion of residual haemodynamic lesions. The modern range of Doppler ultrasound techniques, in particular colour flow mapping, are sensitive methods for the detection of abnormal intracardiac flow patterns. The use of these techniques immediately after bypass can detect even slight flow abnormalities. ${ }^{14}$ In most patients undergoing total correction of congenital heart disease these minimal flow disturbances are not of surgical importance, whereas when the Fontan operation or one of its modifications is performed in patients with complex intracardiac anatomy or in younger patients, even small residual lesions can be clinically important. The immediate detection of these lesions and the subsequent repair during the same operation can improve the early surgical results.

Colour flow mapping allows the detection or definite exclusion of residual intracardiac shunting in most patients. The technique not only shows the existence of residual shunting but also defines the site of origin, which is impossible by any other technique. But the presence of prosthetic material used in the repair causes flow masking. After the creation of a total cavopulmonary connection both the change of the geometry of the right atrium and the use of prosthetic material precluded re- liable colour flow mapping studies performed to exclude residual shunting in two of three patients. Thus after bypass the exclusion of leakage from the intra-atrial tunnel relied entirely on contrast studies. In retrospect we believe that one false positive contrast finding was related to the position of the right atrial line outside the tunnel; because there was an atrial septal defect the line was in what was functionally a pulmonary venous atrium. Sampling for oxygen saturations showed no desaturation and no further steps were taken. The second patient had only one contrast injection into a right atrial line, after which only a few microbubbles appeared in the left atrium after a considerable delay. The finding, though ambiguous, was interpreted as being caused by either pulmonary venous return of microbubbles or generation of an ultrasound contrast effect within the left atrium. A 24 hour postoperative study on the intensive care unit (contrast study and oxygen saturations) showed an important leakage. At reoperation residual communications were identified and subsequently closed. At present only the combination of colour flow mapping, multiple - contrast studies, and sampling for oxygen saturations seems to be of value for the reliable exclusion of shunting after the creation of total cavopulmonary connections. Paediatric transoesophageal probes or "fingertip" probes that allow imaging and colour flow mapping studies from the lateral and posterior aspects of the right atrium may 
solve some of the difficulties of obtaining complete information after this type of operation. To date, however, our experience with these techniques in the intraoperative monitoring of Fontan procedures is limited.

Assessment of blood flow patterns and flow velocities by pulsed wave Doppler allows the immediate exclusion of flow obstruction within the Fontan circulation. Immediately after a direct atriopulmonary connection was established pulsed wave Doppler echocardiography showed biphasic, bidirectional pulmonary blood flow. The biphasic nature of blood flow showed that both the atrial contraction and the left ventricular relaxation contributed to pulmonary blood flow ${ }^{15} 16$ in these patients. In two of three patients in whom the right ventricular chamber was incorporated into the Fontan circulation the pulmonary artery blood flow was greatest during ventricular systole. This finding showed right ventricular augmentation of pulmonary blood flow immediately after bypass, which may be beneficial in the early postoperative period, as was suggested in earlier studies. ${ }^{17-19}$ In the third patient, who had extensive resection of muscular trabeculations between the outlet and the trabecular portions of the right ventricle, pulsed wave Doppler examination did not show a ventricular contribution to pulmonary blood flow. Under these circumstances, and especially when the right ventricle is small, it may become functional some time after repair.

Intraoperative ultrasound provides the surgeon with detailed information on the immediate results of the repair because it can detect slight flow disturbances. It does not measure their haemodynamic importance, however, and this can be misinterpreted. After adequate volume replacement residual obstruction of the outflow tract or interventricular shunting are readily identified. Whereas their severity is often overestimated, the severity of atrioventricular valve regurgitation is more likely to be underestimated when compared with follow up studies. Findings immediately after bypass must be interpreted against the background of the complexity of the pre-existing anomaly and the method of repair. The surgeon must decide whether or not residual haemodynamic lesions need further revision during a second period of bypass. Three of the five patients with documented residual lesions had immediate revision and in all of them the surgical results were good. Studies after bypass and just before closure of the chest in 15 patients and after early reoperation in one patient showed good surgical results in 14 . Precordial studies performed before hospital discharge and clinical follow up excluded significant residual lesions in all patients who had good surgical results as assessed by the final post-bypass study. One patient who required epicardial pacing for atrioventricular block and in whom mitral regurgitation was increased after the Fontan procedure died soon after operation; thus the early hospital mortality in this series was $6 \%$.

In patients with a Fontan circulation even small residual lesions can be detrimental and thus require immediate surgical intervention. Intraoperative ultrasound is useful in assessing the quality of the Fontan repair and the need for reintervention. Its use may further reduce both the need for reoperation and early hospital mortality. In addition, the immediate detection and revision of residual lesions should improve functional results in the longer term.

OS was supported by the Deutsche Forschungsgemeinschaf and NS was supported by the British Heart Foundation.

1 Stellin G, Mazzucco A, Bortolotti U, et al. Tricuspid atresia versus other complex lesions. $J$ Thorac Cardiovasc Surg versus other comp

2 DeLeon SY, Ilbawi MN, Idriss FS, et al. Fontan type operation for complex lesions-surgical considerations to improve survival. $J$ Thorac Cardiovasc Sur 1986;92:1029-37.

3 Ottenkamp J, Rohmer J, Quaegebeur JM, Brom AG, Fontan F. Nine years' experience of physiological correction of tricuspid atresia: long-term results and current surgical approach. Thorax 1982;37:718-26.

4 Annecchino FP, Brunelli F, Borhi A, Abbruzzese P, Merlo M, Parenzan L. Fontan repair for tricuspid atresiaexperience with 50 consecutive patients. Ann Thorac Sur 1988;45:430-6.

5 Laks H, Pearl J, George B, Wu A, Santulli T, Williams R. Experience with the Fontan procedure [Abstract]. $J A m$ Experience with the Fontan
Coll Cardiol 1989;13(2):75A.

6 Leung MP, Benson LN, Smallhorn JF, Williams WG Trusler GA, Freedom RM. Abnormal cardiac signs afte Trusler GA, Freedom RM. Abnormal cardiac signs after Fontan type of operation: indicator
sequelae. Br Heart J 1989;61:52-8.

7 de Vivie ER, Rupprath G. Long-term results after Fontan procedure and its modifications. J Thorac Cardiovasc Surg 1986;91:690-7.

8 Girod DA, Fontan F, Deville C, Ottenkamp J, Choussat A Long-term results after the Fontan operation for tricuspid atresia. Circulation 1987;75:605-10.

9 Eijgelaar A, Hess J, Hardjowijno R, Karliczek GF, Rating W, Homan van der Heide JN. Experience with the Fontan operation. Thorac Cardiovasc Surg 1982;30:63-8.

10 Gussenhoven EJ, van Herwerden LA, Roelandt J, Ligtvoet $\mathrm{KM}$, Bos $\mathrm{E}$, Witsenburg $M$. Intraoperative two-dimensional echocardiography in congenital heart disease. J Am Coll Cardiol 1987;9:565-72.

11 Sutherland GR, van Daele MERM, Stümper OFW, Hess J, Quaegebeur JM. Epicardial and transoesophagea Quaegebeur JM. Epicardial and transoesophageal echocardiography during surgery for congen

12 Ungerleider RM, Greeley WJ, Sheikh KH, Kern FH, Kisslo JA, Sabiston DC. The use of intraoperative echo with Doppler color flow imaging to predict outcome after repair of congenital cardiac defects. Ann Surg 1989;210:526-33.

13 DeLeval MR, Kilner P, Gewillig M, Bull C. Total cavopulmonary connection: a logical alternative to atriopulmonary connection for complex Fontan operations. Experimental studies and early clinical experience. Thorac Cardiovasc Surg 1988;96:682-95.

14 Ungerleider RM, Kisslo JA, Greeley WJ, van Trigt P, Sabiston DC. Intraoperative prebypass and postbypass epicardial color flow mapping in the repair of atrioventricular septal defects. J Thorac Cardiovasc Surg ventricular sept

15 DiSessa TG, Child JS, Perloff JK, et al. Systemic venous and pulmonary arterial flow patterns after Fontan's procedure pulmonary arterial flow patterns after Fontan's procedure for tricuspid atresi

16 Nakazawa M, Nakanishi T, Okuda $H$, et al. Dynamics of right heart flow patterns in patients after Fontan ing

17 Bull C, deLeval MR, Stark J, Taylor JFN, Macartney FJ Use of a subpulmonary ventricular chamber in the Fonta circulation. J Thorac Cardiovasc Surg 1983;85:21-31.

18 Ottenkamp J, Wenink ACG, Quaegebeur JM, et al. Tricuspid atresia-morphology of the outlet chamber with special emphasis on surgical implications. $J$ Thorac Car diovase Surg 1985;89:57-603.

19 McGough E, Thorne K, Boucek M. Right ventricular growth and function following Fontan procedure for tricuspid atresia. 